\title{
A importância da fundamentação teórica em educação nas ações do PIBID: Jogos Didáticos sob uma Perspectiva Freiriana
}

\section{The importance of theoretical foundation in education in the actions of PIBID: Didactic Games under a Freirean Perspective}

SILVA, Marcelo Souza da. Doutor em Física

Instituto Federal de educação Ciência e Tecnologia do Sertão Pernambucano - Campus Salgueiro. BR 232, KM 508, sentido Recife - Salgueiro - Pernambuco - Brasil. CEP: 56.000-000 / Telefone: (87) 3421.0050 / E-mail: marcelo.silva@ifsertaope.edu.br

SOARES, Victor Alves. Licenciado em Física

Instituto Federal de educação Ciência e Tecnologia do Sertão Pernambucano - Campus Salgueiro. BR 232, KM 508, sentido Recife - Salgueiro - Pernambuco - Brasil. CEP: 56.000-000 / Telefone: (87) 3421.0050 / E-mail: victor.alves191@homail.com

RIBEIRO, Daiane Maria dos Santos. Mestra em História Filosofia e Ensino de Ciências

Instituto Federal de educação Ciência e Tecnologia do Sertão Pernambucano - Campus Floresta. Rua Projetada, S/N - Caetano II, Floresta - PE, 56400-000 / Telefone: (87) 3877-2825 / E-mail: daiane.ribeiro@ifsertao-pe.edu.br

FIDELES, Juliana Socorro. Graduanda em Licenciatura em Física

Instituto Federal de educação Ciência e Tecnologia do Sertão Pernambucano - Campus Salgueiro. BR 232, KM 508, sentido Recife - Salgueiro - Pernambuco - Brasil. CEP: 56.000-000 / Telefone: (87) 3421.0050 / E-mail: juliana795@gmail.com

JESUS, Tânia Maria de. Graduanda em Licenciatura em Física

Instituto Federal de educação Ciência e Tecnologia do Sertão Pernambucano - Campus Salgueiro. BR 232, KM 508, sentido Recife - Salgueiro - Pernambuco - Brasil. CEP: 56.000-000 / Telefone: (87) 3421.0050 / E-mail: taniamaria2914@gmail.com

RIBEIRO, Tatyanny Karolinny dos Santos. Graduanda em Licenciatura em Física

Instituto Federal de educação Ciência e Tecnologia do Sertão Pernambucano - Campus Salgueiro. BR 232, KM 508, sentido Recife - Salgueiro - Pernambuco - Brasil. CEP: 56.000-000 / Telefone: (87) 3421.0050 / E-mail: tatyannyribeiro@gmail.com

SANTOS, Gisele Ferreira dos. Especialista em Psicopedagogia

Instituto Federal de educação Ciência e Tecnologia do Sertão Pernambucano - Campus Salgueiro. BR 232, KM 508, sentido Recife - Salgueiro - Pernambuco - Brasil. CEP: 56.000-000 / Telefone: (87) 3421.0050 / E-mail: gizele.ferreira@ifsertaope.edu.br

PAIVA, Getúlio Eduardo Rodrigues de. Mestre em Engenharia Elétrica

Instituto Federal de educação Ciência e Tecnologia do Sertão Pernambucano - Campus Salgueiro. BR 232, KM 508, sentido Recife - Salgueiro - Pernambuco - Brasil. CEP: 56.000-000 / Telefone: (87) 3421.0050 / E-mail: e- getulio.paiva@ifsertaope.edu.br

RESUMO

Neste artigo, analisou-se a presença explícita da fundamentação teórico-pedagógica nas produções-ações dos bolsistas do Programa Institucional de Bolsas de Iniciação à Docência (PIBID). Para tanto, executou-se um breve levantamento bibliográfico dos trabalhos publicados pelos bolsistas (pibidanos) do Instituto Federal do Sertão Pernambucano campus Salgueiro, buscando identificar quais foram os referenciais teóricos da área da educação nos quais se fundamentaram esses trabalhos. Foram estudados textos produzidos entre os anos de 2013 a 2016; após essa breve revisão, descreveu-se uma ação de produção de jogos didáticos desenvolvida por alunos bolsistas do Subprojeto de Física do PIBID, nesse exemplo, os jogos didáticos foram criados adotando Paulo Freire como principal referência.

Palavras-chave: Desafios, Jogos didáticos, Ensino de Ciências.

\section{ABSTRACT}

In this article, we analyzed the explicit presence of the theoretical-pedagogical foundations in the productions-actions of the scholarship students of the Institutional Program of Initiation to Teaching (PIBID). Therefore, a brief bibliographic survey of the works published by the scholars) of the Federal Institute of the Sertão Pernambucano campus Salgueiro, trying to identify which were the theoretical references of the area of education on which these works were based. We studied texts produced between the years of 2013 and 2016; after this brief review, a production of didactic games developed by scholarship students of the PIBID Physics Subproject was described, in this example, the didactic games were created by adopting Paulo Freire as the main reference.

keywords: Challenges, Didactic games, Science education. 
SILVA, M. S. da;. et. al (2019)

A importância da fundamentação teórica em educação nas ações do PIBID: Jogos Didáticos sob uma Perspectiva Freiriana

\section{Introdução}

Para pensar-praticar uma educação crítica e transformadora é necessário ultrapassar a inércia atual do ensino; no caso particular do ensino de Ciências, as atividades ainda são estáticas, e mesmo os professores com formação adequada, em geral, restringem-se, apenas, a "transmitir" um conhecimento previamente elaborado ou a "elaborar" estratégias ditas diferenciadas que, na maioria dos casos, não permitem aos estudantes um estudo exploratório, criativo e reflexivo (MORIN, 2000; RIBEIRO et al., 2015). Desde as séries iniciais até o nível universitário, a educação científica tem sido reduzida, basicamente, à apresentação de conhecimentos previamente elaborados, que são histórica e socialmente não referenciados (RIBEIRO; SILVA, 2015), nesse sentido, percebendo-se que, embora se faça uma defesa em prol da educação inovadora, progressista, emancipatória e libertadora, esbarra-se muitas vezes em práticas conservadoras, com isso, evidenciando um conflito entre o pensar e o fazer.

No campus Salgueiro do Instituto Federal de Educação, Ciência e Tecnologia do Sertão Pernambucano (IF SERTÃO-PE), o Programa Institucional de Bolsas de Iniciação à Docência (PIBID) ajuda os alunos do curso de Licenciatura em Física a desenvolverem trabalhos como práticas pedagógicas participando da vivência dos professores, opõe lhes oportuniza um aperfeiçoamento como futuros professores, incentivando a consolidação de uma cultura educacional diferenciada, que articula interações de três diferentes perspectivas de formação: um conhecimento de senso comum - principalmente por parte dos licenciados-; dos saberes acadêmicos - prioritariamente por parte dos professores das instituições de Ensino Superior (IES) -; e do contexto escolar proveniente, mormente dos saberes empíricos dos professores das escolas do ensino fundamental (AMORIM; VIEIRA, 2016).

Antes de desenvolver uma prática pedagógica é necessário que o estudante de licenciatura tenha alguma noção sobre a educação e, para isso, é fundamental o conhecimento do trabalho de teóricos da educação. Ao bem fundamentar seus trabalhos acadêmicos, o estudante terá maiores possibilidades detratar seu tema investigativo com coerência, de maneira aprofundada, permitindo assim que os próprios autores exercitem uma leitura de mundo de forma crítica. Posto isso, destacase que este trabalho tomou como base a pedagogia de Paulo Freire, que é o mais influente pensador educacional brasileiro no cenário mundial. O seu livro "Pedagogia do oprimido" foi traduzido para mais de 20 idiomas e consta como um dos cem livros mais citados do mundo. A obra freiriana influencia estudos desenvolvidos por intelectuais de diferentes áreas do conhecimento (pedagogia, filosofia, antropologia, serviço social, ecologia, medicina, psicologia, jornalismo, artes, ciência política, etc.), mundialmente, há mais de 30anos (DOS SANTOS, 2009). Na perspectiva freiriana é fundamental o rompimento de uma visão fragmentária de mundo e de educação, portanto, uma ideia mais integradora na construção do conhecimento e na prática educativa deve ser buscada em um ambiente no qual novos saberes e distintas atitudes sejam construídos em práticas sociais diferenciadas: 
SILVA, M. S. da; . et. al (2019).

A importância da fundamentação teórica em educação nas ações do PIBID: Jogos Didáticos sob uma Perspectiva Freiriana

Mulheres e homens somos os únicos seres que, social e historicamente, nos tornamos capazes de aprender. Por isso, somos os únicos em quem aprender é uma aventura criadora, algo, por isso mesmo, muito mais rico do que meramente repetir a lição dada. Aprender para nós é construir, reconstruir, constatar para mudar, o que não se faz sem abertura ao risco e à aventura do espírito. (FREIRE, 2002, p.77).

Este trabalho teve como objetivo fazer um levantamento bibliográfico breve dos trabalhos publicados pelos alunos do PIBID de Salgueiro e, com isso, individuar, nesses trabalhos, quais foram os referenciais teóricos da área da educação utilizados; esses trabalhos foram publicados em encontros nacionais e regionais voltados para o ensino de Ciências. Para tanto, partiu-seda hipótese que qualquer abordagem educativa deve conter pressupostos teóricos ou concepções implícitas sobre educação. Com base nessa hipótese, fez-se o levantamento comparando os artigos, bem como, para melhor exemplificar a ideia de fundamentar ações de estudo, vivência e produção em uma teoria pedagógica, descreveu-se uma intervenção, a produção de jogos didáticos, referenciada no pensamento freiriano.

\section{Avaliação dos trabalhos produzidos pelo PIBID de 2013 a 2016}

O Trabalho-I, publicado em 2013, intitulado Um prisma como ferramenta didática para o ensino de ótica geométrica no ensino médio, buscou utilizar uma abordagem histórica do que é a ótica, deixando bem claro, no objetivo, que se pretendera fazer o esboço de uma aula em que o professor utilizava um prisma ótico para explicar, deforma didática, a refração da luz. A parte histórica do trabalho relata como cientistas dos séculos XV e XVI trabalhavam com o prisma. Então, percebe-seque os autores buscam utilizar a história da ciência como recurso didático, entretanto, no desenvolvimento da metodologia, não se aprofunda nem sequer tenta-se explicar detalhes da utilização da história da ciência como recurso didático.

Não obstante, os autores não indicamos documentos históricos que serviram de fundamento para essa isenção da história da filosofia da ciência. O prisma aparentemente é produzido com material de baixo custo, e os autores concluem que os resultados foram satisfatórios com a aprendizagem dos estudantes, mas não define o entendimento adotado para o conceito central da conclusão, a aprendizagem. Portanto, não esclarecem como foi possível concluir que ela era satisfatória. Eles ainda concluem que os alunos tiveram oportunidade de desenvolver intelectualmente, da mesma maneira, sem definir o que é desenvolvimento intelectual e como eles estudaram essa evolução no desenvolvimento intelectual dos alunos. Finalmente, não há, nas referências do trabalho, uma explícita citação de teorias da pedagogia (VERAS, 2013).

No Trabalho-II, também, publicado no ano de 2013, intitulado Relato de experiência dos bolsistas do PIBID do curso de licenciatura no Erem Aura Parente Muniz, relata-se a contribuição do PIBID do IF SERTÃO-PE campus Salgueiro na formação do bolsista como futuro professor e educador. 0 artigo foi desenvolvido em parceria com a escola estadual. Os autores fazem um relato de experiência do licenciando ao ir até uma instituição de nível médio desenvolver atividades 
SILVA, M. S. da; . et. al (2019).

A importância da fundamentação teórica em educação nas ações do PIBID: Jogos Didáticos sob uma Perspectiva Freiriana

relacionadas à docência, o trabalho faz a discussão do que é o PIBID, qual é sua intenção e a importância de interação das escolas. É citada explicitamente a intenção das metodologias de facilitar o acesso ao processo de ensino e aprendizagem, refere-se ao processo de aprendizado (no sentido da intervenção pedagógica), atribuindo-lhe o objetivo de buscar uma "forma teórica sólida". Essas afirmações apresentam concepções conteudistas implícitas e de um pensamento pragramático, tradicionalista e excludente no que tange ao processo pedagógico centrado no ensino. Conquanto isso esteja implícito no texto, os autores não tentam definir o que seria o "processo de ensino" e "formação sólida", eles colocam como objetivo, mas não situam esses conceitos como base em qualquer teoria educacional. No objetivo do trabalho é relatada a tentativa de valorizar e incentivar a formação do educador em Física, argumentando que com essa valorização o aluno teria a oportunidade de isenção no mercado de trabalho. Fica bem claro que este trabalho apenas reproduz quais são os objetivos do PIBID. 0 trabalho-II apresenta a pesquisa em educação e objetivos do programa PIBID como sinônimos, e como resultado restringe-se a fazer uma reprodução do que é o objetivo do programa e, aparentemente, faz uma descrição do que vem a ser o PIBID. Novamente, aparecem sinais de uma concepção tecnicista, de uma concepção conteudista na descrição da elaboração de apostila com assuntos de Física, não há, em momento algum, uma definição teórica dos conceitos centrais (OLIVEIRA et al., 2013).

No Trabalho-III, Construção de lunetas de baixo custo para trabalhar astronomia no ensino de Física, publicado no ano de 2015 , os autores defendem que as atividades constituem um fator importante no ensino de Ciências, pois existe a potencialidade de desenvolver, principalmente, as possíveis especificidades, todavia sem definir quais sejam essas especificidades. É apresentada a ideia de que apenas assistindo a aulas teóricas nem sempre os alunos conseguem identificar o caráter prático e investigativo. Ao analisar, percebe-se que os autores tentam defender uma predisposição de fazer atividades práticas, porém não apresentando uma definição do que vem a ser teoria e prática, aparentemente, o trabalho aponta a aula prática como garantia de aprendizado; e a aula teórica, como uma aula ultrapassada. Na seção de materiais e métodos, o artigo traz uma descrição de como montar as lunetas, com um viés fortemente tecnicista, sugerindo um passo a passo, em que os alunos devem meramente reproduzir as instruções. Nas considerações finais, os autores referem que os alunos envolvidos gostaram da forma que a astronomia foi abordada, entretanto não deixam claro como esse gostar foi avaliado, eles afirmam que o trabalho foi relevante para o aprendizado sem, contudo, definir um referencial mediante o qual se possa entender essa aprendizagem (SILVA et al., 2015).

O Trabalho-IV, A contribuição do PIBID na escola estadual Carlos Pena Filho através da jornada de foguetes, publicado em 2015, apresenta um relato de experiência de atividades relacionadas ao lançamento de foguetes. Os autores colocam o professor como um intermediário do conhecimento e sugerem a relação de ensino e aprendizagem como indissociável. Além disso, esse trabalho aponta como função do PIBID, nas licenciaturas, a de desenvolver atividades pedagogicamente diversas, entretanto não existe uma fundamentação do que seria essa diversidade pedagógica. Na seção de materiais e métodos, o par dialógico professor-aluno aparece, e isso sugere também influência da pedagogia freiriana por conta do destaque em relação ao contexto social dos 
SILVA, M. S. da;. et. al (2019)

A importância da fundamentação teórica em educação nas ações do PIBID: Jogos Didáticos sob uma Perspectiva Freiriana

alunos, entretanto esses aspectos não são definidos de modo nenhum no trabalho,são apenas citados. Aparentemente, as atividades também são pensadas em termos de colocações que os alunos fizeram, é relatado ainda que os alunos receberam pontos para participar da atividade, mostrando assim a convivência de um discurso progressista, pensando uma educação inovadora em contraposição a uma prática mais conservadora. Nas considerações finais, os autores inferem que as expectativas foram alcançadas por conta das atividades práticas e do relatório, porém eles não discutiram quais foram esses resultados, defendem a presença dos bolsistas na escola assim como é feito nas premissas do PIBID e novamente pontuam que as atividades didáticas orbitaram em torno dos problemas levados pelos alunos. Concluem retomando as questões com foco em memorização de conteúdos, evidenciando uma possível convivência de contradições pedagógicas, as referências bibliográficas apresentadas corroboram essa interpretação (SAMPAIO et al., 2015).

O Trabalho-V, publicado em 2015, intitula-se: Relato de experiência do PIBID discutindo um questionamento com os alunos do ensino médio no lançamento de garrafa PET. No título, percebe-se uma diferenciação dos trabalhos anteriores, pois esse trabalho desenvolveu-se em torno de um questionamento feito pelos estudantes, e isso sinaliza uma mudança na tendência percebida anteriormente, que os estudantes participavam passivamente das atividades. Esse trabalho descreve um relato de experiência realizado no lançamento de foguete, com isso, focalizando um fenômeno observado por um dos alunos atendidos, explicando a realização da oficina de foguete e descrevendo a metodologia de como foram produzidos os foguetes; por sua vez, a avaliação dos resultados levanta a dúvida geradora da atividade.Os autores colocam o aluno no centro do processo ensino-aprendizagem, entretanto não há fundamentação teórica a respeito dessas concepções que aparentemente são subjacentes à visão dos autores. Na discussão, os autores destacam o empenho e a motivação dos estudantes. Esse empenho foi avaliado utilizando um parâmetro da quantidade de vezes que eles pediram ajuda e posicionaram-se. É destacado pelos autores que, ao levar essas discussões para a sala de aula, a relação que se estabeleceria entre professores e alunos seria uma relação dialógica, mas não abordam com que profundidade ou hierarquização ocorre tal relação entre os sujeitos do processo. Os alunos associam práticas diferenciadas e divertidas ao ambiente fora da sala de aula, ambientes não formais, etc. Os autores concluem afirmando que têm como público-alvo estudantes do Ensino Fundamental e Médio e que as atividades se desenvolveram em torno das questões colocadas pelos alunos. É importante destacar que esse é o primeiro artigo no qual aparecem autores como Paulo Freire e Marcos Antônio Moreira, considerados fortes referências em educação e ensino de Ciências no Brasil. (SILVA et al., 2015).

Em 2015, foi publicado o Trabalho - VI intitulado: 0 uso de publicações cientificas como ferramenta motivacional na construção da prática docente. Nesse trabalho, os autores expõem uma experiência pedagógica desenvolvida na disciplina de Física I, voltada aos estudantes do curso de Licenciatura em Física, do primeiro ano. 0 autor busca apresentar a visão dos estudantes diante da complexa realidade da formação docente visando construir estratégias didáticas. Esse trabalho procurou estabelecer uma definição do ensino tradicional como um ensino que não satisfaz as curiosidades cotidianas dos estudantes e apenas reproduz um saber pronto. A definição para o ensino tradicional apontada no artigo é referenciada em uma publicação sobre física, e não sobre 
SILVA, M. S. da; . et. al (2019).

A importância da fundamentação teórica em educação nas ações do PIBID: Jogos Didáticos sob uma Perspectiva Freiriana

educação. Os autores falam sobre competências e habilidades, mas apresentam concepções conteudistas. Aparentemente, o trabalho foi escrito sem o devido referencial teórico, três artigos com diferentes abordagens sobre cinemática foram selecionados pelo professor da disciplina, cada aluno fez uma prática baseado nos artigos, são artigos de experimentos e abordam uma percepção histórica com ideia de uma prática pedagógica diferenciada, contudo repete-se a questão de não deixar clara a teoria pedagógica sob a qual se fundamentou essa prática; concluindo, por fim, que os objetivos foram atingidos. Conforme os autores, foi possível identificar aspectos qualitativos e positivos relacionados à compreensão do conteúdo, porém sem a descrição de como a avaliação em relação aos aspectos indicados, pelos autores como "positivos e qualitativos" foi feita (CIQUEIRA et al., 2015).

No Trabalho-VII, publicado em 2016, intitulado: A importância da utilização de laboratório de ciências na solidificação do conhecimento na área de Física, os autores destacam a importância de o aluno ter aula no laboratório, mas hierarquizam a relação teoria-prática,e enfatizam isso ao referir que as atividades experimentais são uma aplicação prática da teoria e que isso possibilita uma aprendizagem mais coerente. 0 objetivo do trabalho foi o de discutir se o laboratório estava sendo utilizado nas aulas de Física, mas pouco se descreve o como, sendo que os autores dão a entender que, ao utilizar o laboratório, os problemas das atividades experimentais estariam resolvidos. Na metodologia foi aplicado um questionário de pré-teste antes da realização do experimento e, ao fim do experimento, foi aplicado outro questionário com o objetivo de medir o aproveitamento da aula no laboratório.Os resultados foram analisados através de uma tabela, e eles concluíram que houve um aumento de acertos, atribuídos à atividade experimental. Tal conclusão, porém, percorre um caminho metodológico questionável. Foi pontuado também que a atividade despertou curiosidade, mas não definem como isso foi avaliado. Esse trabalho não apresenta referências teóricas da área de educação. (LEAL et al., 2016).

O quadro1 sumariza alguns aspectos observados na breve revisão de literatura dos trabalhos do PIBID publicados entre 2013 e 2016, pelos bolsistas do campus Salgueiro-PE.

Quadro 1: Aspectos observados nas publicações do PIBID do IF SERTÃO-PE -campus Salgueiro.

\begin{tabular}{cccccc}
\hline Publicação & $\begin{array}{c}\text { Fala sobre } \\
\text { didática ou } \\
\text { aprendizado }\end{array}$ & $\begin{array}{c}\text { Propõe a } \\
\text { utilização de } \\
\text { alguma } \\
\text { ferramenta } \\
\text { didática }\end{array}$ & $\begin{array}{c}\text { Define um } \\
\text { conceito de } \\
\text { aprendizagem. }\end{array}$ & $\begin{array}{c}\text { Participação } \\
\text { dos estudantes } \\
\text { de forma ativa. }\end{array}$ & $\begin{array}{c}\text { Utiliza } \\
\text { explicitamente um } \\
\text { teórico da } \\
\text { educação. }\end{array}$ \\
\hline Trabalho I & $\mathbf{X}$ & $\mathbf{X}$ & & & \\
\hline Trabalho II & $\mathrm{X}$ & $\mathrm{X}$ & & & \\
\hline Trabalho III & $\mathrm{X}$ & $\mathrm{X}$ & & & \\
\hline Trabalho IV & $\mathrm{X}$ & $\mathrm{X}$ & $\mathbf{X}$ & $\mathbf{X}$ & \\
\hline Trabalho V & $\mathbf{X}$ & $\mathbf{X}$ & & $\mathrm{X}$ & \\
\hline Trabalho VI & $\mathrm{X}$ & $\mathrm{X}$ & $\mathrm{X}$ & & \\
\hline Trabalho VII & $\mathrm{X}$ & $\mathrm{X}$ & & & \\
\hline
\end{tabular}

Fonte: própria 
SILVA, M. S. da;. et. al (2019).

A importância da fundamentação teórica em educação nas ações do PIBID: Jogos Didáticos sob uma Perspectiva Freiriana

É possível destacar que, de um modo geral, os artigos não se fundamentaram explicitamente em qualquer teórico da educação e que, conquanto todos apresentem o termo aprendizagem, comumente, não fica claro o que esses autores entendem ou qual entendimento adotam acerca desse conceito central. O PIBID contribui para o preenchimento de lacunas na formação inicial de professores que demandam, além da vivência do espaço escolar, a experiência do saber acadêmico, necessitando de fundamentação acerca de teorias pedagógicas. 0 quadro 1, também,possibilita entender que as publicações mais recentes têm refletido práticas pedagógicas mais coerentes com o discurso progressista, pois, em geral, defendem ideias educacionais mais centradas na aprendizagem e suas ações corroboram para que o estudante assuma o papel de autor.

Feita essa análise dos trabalhos desenvolvidos no âmbito do PIBID, pelos bolsistas do IF SERTÃO-PE, campus Salgueiro, verificou-se que em praticamente todos os artigos há uma preocupação com a aprendizagem, e, nesse sentido, eles, comumente, propõem atividades educativas centradas no ensino, todavia os próprios autores não aprofundam, definem ou discutem sobre o conceito de aprendizagem adotado nos trabalhos ou, ainda que se refiram a uma ideia de aprendizagem, implicitamente, suas ações sugerem compreensões opostas. Essa observação revela que, para além da necessidade de abordar mais profundamente temas, autores, pensadores, correntes filosóficas, etc. relacionados a teorias da educação na formação de professores, é necessário vivenciar a práxis educacional fundamentada nas teorias, é necessário percorrer um caminho coerente entre o que se propõe e o que se executa, não de forma pontual, mas contínua e paulatinamente, em ações que se definem,aqui, como Cultura Educacional Fundamentada (CEF). Para exemplificar uma alternativa possível de como viver essa CEF. No presente trabalho, a título de exemplo, propôs-se o desenvolvimento de uma prática pedagógica pautada por um referencial teórico claro e específico. Dentre as possibilidades, os autores optaram pela construção de um jogo didático apoiado na teoria pedagógica freiriana.

\section{Exemplo de CEF: Paulo Freire fundamenta jogos didáticos}

Inicialmente, aos alunos matriculados na disciplina Oficina de Física I, componente curricular do curso de Licenciatura em Física, destinada ao estudo e à produção de recursos didáticos (experimentos, filmes, objetos educacionais, etc.), dever-se-ia apresentar esses recursos em uma aula simulada. Assim, foram esses produzidos e foi simulada sua aplicação, durante a simulação de aplicação dos recursos, percebeu-seque tais recursos didáticos apresentavam um caráter meramente demonstrativo, serviam para confirmar um conteúdo dado em sala de aula. Diante de tal constatação, uma série de questionamentos foi levantada pelo professor no sentido de fomentar uma reflexão acerca da prática pedagógica desenvolvida na simulação. Os próprios licenciandos reconheceram que estudam temas sobre didática, teorias de aprendizagem, políticas públicas educacionais, etc., mas não conseguem extrapolar esses saberes para suas práticas pedagógicas. "Para mim, é quase automático dar as aulas iguais as que eu tive" - afirma um dos estudantes. Ao compreender isso como uma dificuldade, o grupo levantou sugestões para superá-la. 
SILVA, M. S. da;. et. al (2019)

A importância da fundamentação teórica em educação nas ações do PIBID: Jogos Didáticos sob uma Perspectiva Freiriana

Os licenciandos deveriam estudar alguma teoria pedagógica e criar um recurso didático, mas o próprio processo de criação deveria estar, o tanto quanto possível, de acordo com a fundamentação estudada. Assim, escolheu-se estudar Paulo Freire e produzir jogos como um exemplo de fundamentação teórica para prática pedagógica, bem como implementação extensiva da CEF. A seguir, discute-se a produção desses jogos didáticos pautados no pensamento freiriano.

Criar um jogo para ser utilizado como ferramenta didática constituiu-se, por si, em uma atividade educativa coletiva protagonizada pelos licenciandos e pelo professor da disciplina de Oficina de Física I, em que se deu o aperfeiçoamento contínuo do desenvolvimento do jogo, buscando, então, identificar os pontos fracos e as devidas mudanças visando dar coerência à rotina ação-reflexão-ação. Para produzir jogos de acordo coma perspectiva de Paulo Freire, muitas práticas tiveram de ser repensadas, entre elas, o foco nos conteúdos. Freire (2002) critica a ideia de que ensinar é transmitir conhecimento. Para ele é fundamental o entendimento de que o professor deve atuar como um agente dialógico na criação, recriação e significação de conhecimentos. Segundo Freire (2002), o profissional de educação deve proporcionar aos estudantes um conhecer dos temas de estudos como uma interpretação vinculada a uma leitura do mundo, ou seja, os assuntos não são verdades absolutas. As propostas de ações educativas de Paulo Freire não visam apenas tornar mais rápido e acessível o aprendizado, mas pretendem habilitar o aluno a "ler o mundo", na expressão famosa do educador. "Trata-se de aprender a ler a realidade (conhecê-la) para em seguida poder reescrever essa realidade (transformá-la)". Nessa perspectiva, os saberes do aluno são fundamentais, pois constituem uma parte da forma de como eles vêem o mundo, assim, com um diálogo entre todos os envolvidos no processo educativo é que acontece, indissociavelmente, a aprendizagem e o ensino, quem ensina aprende ao ensinar, e quem apreende ensina ao aprender, por conseguinte, todos os envolvidos devem ser tratados como sujeitos ativos desse processo, como iguais (FREIRE, 1987). Essas características de leitura do mundo, consideração dos saberes do estudante e igualdade ao longo do processo ensino-aprendizagem, com base na pedagogia freiriana, foram adotadas para a criação de jogos como materiais didáticos.

O desafio era buscar uma abordagem que valorizasse os saberes de Física e Matemática relacionados ao magnetismo e interligados com as questões sociais e as experiências individuais dos estudantes. Objetivava-se um desenvolvimento de atividade que estimulasse a intervenção coletiva dos alunos, que essa fosse crítica aos conteúdos, uma participação empreendedora e criativa em busca da solução de problemas, com consciência de que o saber científico é ideológico e não neutro, ou seja, trata-se de aceitação de paradigmas dentro de uma sociedade que não está pronta e de que todos podem colaborar para sua construção. Exemplifica-se, a seguir, algumas das ideias desenvolvidas,afigura 1-a mostra uma cartela inacabada do jogo "Bingo da Eletricidade e Magnetismo"; os números na cartela foram substituídos por conceitos, existem casas vazias em que os jogadores precisam escrever palavras que eles associam ao tema em estudo, cada número sorteado corresponde a uma questão, situação ou interpretação que deve ser ligada ao termo da cartela. Quem marcar uma linha ou coluna assume o sorteio dos números, de forma que todos passem por todas as cartelas, o jogo termina quando todas as cartelas forem preenchidas. A figura 1- b apresenta uma trilha, é jogado com quatro pessoas de cada vez. Os peões devem cruzar a linha 
SILVA, M. S. da;. et. al (2019).

A importância da fundamentação teórica em educação nas ações do PIBID: Jogos Didáticos sob uma Perspectiva Freiriana

de chegada, para avançar, cada vez que se lança o dado, o jogador deve responder às questões que o grupo elaborou, e as respostas devem ser avaliadas pelo coletivo. 0 jogo acaba quando todos concluírem o percurso.

Figura 1: (a) Exemplo de cartela: Bingo da Eletricidade e do Magnetismo, (b) Jogo Trilha do Magnetismo.

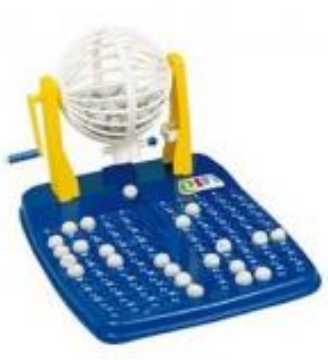

Bingo da eletricidade e magnetismo

\begin{tabular}{|l|l|l|l|}
\hline $\begin{array}{l}\text { Carga } \\
\text { elétrica }\end{array}$ & Motor & $\begin{array}{l}\text { Eletro- } \\
\text { domésticos }\end{array}$ & \\
\hline Imà & & \\
\hline & & \\
\hline & & & \\
\hline
\end{tabular}

(a)

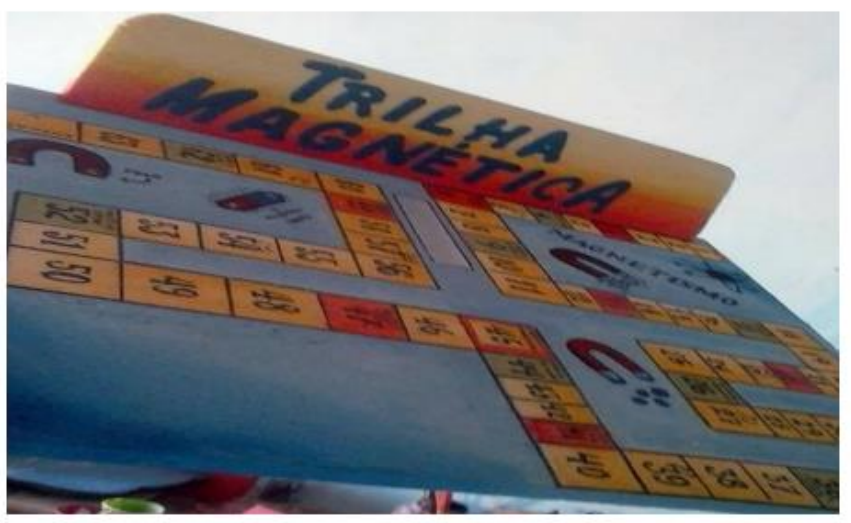

(b)

Fonte: Arquivo do autor (2017).

Os jogos produzidos apresentam alguns aspetos importantes: não há apenas um vencedor, todos podem vencer, todos podem adquirir conhecimento, tanto a trilha quanto o bingo não têm respostas prontas para perguntas prontas;as perguntas e as respostas são produzidas e aceitas ou refutadas coletivamente, assim, há espaço para um diálogo entre os diferentes saberes de cada um dos envolvidos. 0 processo de ensino-aprendizagem ocorre gradativamente, conforme um contexto 
SILVA, M. S. da;. et. al (2019)

A importância da fundamentação teórica em educação nas ações do PIBID: Jogos Didáticos sob uma Perspectiva Freiriana

que não descarta o que o estudante já sabe, dessa forma, aos poucos, os novos saberes vão adquirindo significado e ampliando a visão de mundo dos envolvidos.

A aplicação didática dos jogos requer uma sequência de atividades para possibilitar a contextualização dos temas com a realidade vivenciada pelos estudantes e para praticar a habilidade crítica e reflexiva de pensar sobre problemas sociais que envolvam tais temas.

\section{Conclusões}

O levantamento dos trabalhos publicados revelou um aparente distanciamento entre o que os autores licenciandos pregam e suas práticas. Todavia, neste estudo, acredita-seque esse processo contraditório é uma fase natural de reestruturação do saber. De um modo geral, todos os trabalhos referem-se à aprendizagem, mas a concepção desse conceito não passa de uma ideia vaga da interpretação tradicionalista da educação bancária, ou seja, os pibidianos pautam suas intervenções em um modelo centrado no ensino. Com a avaliação dos trabalhos do PIBID, foi possível verificar uma evolução na fundamentação teórica desses no que tange aos saberes da área pedagógica. Portanto, é possível afirmar, em linhas gerais, que o PIBID propicia excelentes oportunidades para aprofundar, conjuntamente, licenciandos, professores das IES e professores da educação fundamental, o entendimento do conceito de aprendizagem.

Foi possível estabelecer uma atividade de produção dos jogos com base na pedagogia freiriana.Esses jogos foram desenvolvidos em um processo de aplicação-reformulação-aplicação que possibilitou aos licenciandos aprenderem-ensinarem criticando sua própria produção, dessa forma, eles puderam vivenciar um ambiente de CEF.

As principais características do pensamento de Paulo Freire que ecoaram na concepção dos jogos foram: o caráter de cooperação mediante a qual todos podem vencer, o caráter no qual, alem do conteúdo é dado relevância dimensões como habilidades de síntese, análise, etc., a inexistência de respostas prontas, a participação ativa do educando ajudando a compor e avaliar coletivamente. Contudo é importante destacar que essas características não devem ser confundidas com os jogos propriamente ditos, elas só se materializam enquanto uma realidade educacional devido à atitude dos educadores frente ao processo de ensino-aprendizagem, ou seja, se não houver uma mudança de postura dos agentes professores e alunos, o jogo em si não terá serventia. Em outras palavras: o jogo didático não representa a solução definitiva para o ensino de Ciências, não é o jogo que pensa em incluir o excluído, libertar o oprimido, ampliar a leitura domundo, criticar a realidade vivida, etc.; essa tarefa é destinada a cada homem e mulher envolvidos no processo educativo. Conclui-se, então, que é imprescindível que todos e todas que constroem os processos educativos ampliem suas percepções a respeito da educação e do ensino-aprendizagem, para tanto, fundamentando suas ações e aproximando o discurso às suas práxis. 
SILVA, M. S. da;. et. al (2019).

A importância da fundamentação teórica em educação nas ações do PIBID: Jogos Didáticos sob uma Perspectiva Freiriana

\section{Referências}

AMORIM, D. C. G.; VIEIRA J N. Enfoques epistemológicos do programa institucional de bolsa de iniciação à docência/PIBID na formação docente. Semiárido De Visu, v. 4, n. 3, p. 132-145, 2016.

DOS SANTOS, W. L. P. Scientific literacy: A Freirean perspective as a radical view of humanistic science education, Science Education, v. 93, n. 2, p. 361-382, 2009. FREIRE, P. Pedagogia do Oprimido. Rio de Janeiro: Paz e Terra, 1987.

Pedagogia de Autonomia. Saberes necessários à prática educativa. São Paulo: Paz e Terra,2002.

LEAL, M. B. C.et al. A importância da utilização do laboratório de ciências na solidificação do conhecimento na área da Física In: IV JORNADA DE INICIAÇÃO A DOCÊNCIA. Anais... 2016. SalgueiroPE: 2016.

MENEZES,E. J. Et. A pedagogia de Paulo Freire em Atividades com jogos de matemáticas: Educação,Autonomia e cidadania. Canoas, 2013.

MORIN, E. Os Sete Saberes necessários à Educação do Futuro. 2. ed. SãoPaulo: Cortez, 2000.

OLIVEIRA, A. C. B. et al. Relato de experiência dos bolsistas do PIBID do curso de física no Erem Aura Parente Muniz. In: XXXI ENCONTRO DE FíSICOS DO NORTE E NORDESTE, 2013. Anais. Campina Grande-PB: SBF, 2013.

RIBEIRO, D. M. S. et al. Radioatividade: o que pensam os visitantes do museu de ciência Antônio Carneiro em Salgueiro-PE. Caderno de Física da UEFS,v. 13, n. 02, p.2501.1-9, 2015.

RIBEIRO, D. M. S.; SILVA, M. S. Textos de Divulgação Científica: uma intervenção para aprofundar as concepções epistemológicas de professores e estudantes de Física. Acta Scientiae, v. 17.3, 2015.

SAMPAIO, D. J. F. et al. Contribuições do pibid na escola estadual Carlos Pena Filho através da jornada de foguetes In: XXXIII ENCONTRO DE FíSICOS DO NORTE E NORDESTE, 2015. Anais. Natal-RN: SBF, 2015.

SILVA, E. C. et al. Oficina de física: construção de lunetas de baixo custo para trabalhar astronomia no ensino de física.In:V SEMINÁRIO BAIANO DAS LICENCIATURAS, V SEMINÁRIO ESTADUAL PIBID-IAT E I SEMINÁRIO PIBID DO NORDESTE, 2015. Anais. Salvador-BA: 2015. 
SILVA, M. S. da;. et. al (2019).

A importância da fundamentação teórica em educação nas ações do PIBID: Jogos Didáticos sob uma Perspectiva Freiriana

SILVA, M. L. et al. Relato de experiência no PIBID: discutindo um questionamento com alunos do ensino médio no lançamento de foguetes de garrafa pet In: XXXIII ENCONTRO DE FÍSICOS DO NORTE E NORDESTE, 2015. Anais. Natal-RN: SBF, 2015.

SIQUEIRA, L. C. C. et al. Publicações científicas na construção da prática docente: a perspectiva de licenciandos em física do IF Sertão-PE In: XXXIII ENCONTRO DE FÍSICOS DO NORTE E NORDESTE, 2015. Anais. Natal-RN: SBF, 2015.

VERAS, K. et al. Um prisma como ferramenta didática para o ensino de ótica geométrica no ensino médio.In: III JORNADA DE INICIAÇÃO À DOCÊNCIA, 2013. Anais. Petrolina-PE: 2013. 